\title{
Water uptake analysis of acceptor-doped lanthanum orthoniobates
}

\author{
Aleksandra Mielewczyk-Gryń ${ }^{1}$ (1) Sebastian Wachowski ${ }^{1} \cdot$ Marta Prześniak-Welenc ${ }^{1} \cdot$ Kacper Dzierzgowski $^{1}$. \\ Anna Regoutz ${ }^{2}$. David J. Payne ${ }^{2} \cdot$ Maria Gazda $^{1}$
}

Received: 11 July 2018/Accepted: 22 March 2019/Published online: 5 April 2019

(C) The Author(s) 2019

\begin{abstract}
In this work, lanthanum orthoniobates doped with either antimony, calcium, or both have been synthesized and studied. The water uptake of the investigated materials has been analyzed by means of thermogravimetric studies. The results show the difference between the thermodynamics of hydration between the lanthanum orthoniobate system and other proton conducting ceramics. The relation between the water uptake and effective acceptor doping for the investigated system has been found, and the energetics of the water uptake relation are discussed.
\end{abstract}

Keywords Proton conductors · Thermogravimetry · Water uptake $\cdot$ Hydration

\section{Introduction}

Lanthanum orthoniobate is a well-recognized proton-conducting oxide with potential applications in electrochemical devices [1-4]. The prospective applications have attracted attention to this oxide because of its chemical stability and, what is even more important, pure proton conductivity across a wide range of temperatures [3]. Therefore, the understanding of phenomena associated with this compound is crucial. As in most of proton-conducting ceramics, the ionic conductivity of lanthanum orthoniobate relies on protonic defect formation:

$\mathrm{H}_{2} \mathrm{O}+V_{\mathrm{O}}^{\ddot{O}}+\mathrm{O}_{\mathrm{O}}^{\mathrm{x}} \leftrightarrow 2 \mathrm{OH}_{\mathrm{O}}$

The number of protonic defects present in the oxide structure depends on the concentration of oxygen vacancies. Vacancies may be formed either as intrinsic defects, or they may be introduced by acceptor doping. In the case

Electronic supplementary material The online version of this article (https://doi.org/10.1007/s10973-019-08208-6) contains supplementary material, which is available to authorized users.

Aleksandra Mielewczyk-Gryń

alegryn@pg.edu.pl

1 Department of Solid State Physics, Faculty of Applied Physics and Mathematics, Gdańsk University of Technology, Narutowicza 11/12, 80-233 Gdańsk, Poland

2 Department of Materials, Faculty of Engineering, Imperial College London, Exhibition Road, London SW7 2AZ, UK of lanthanum orthoniobate, a dopant can be incorporated on both lanthanum and niobium sites [3-6]. Acceptor doping on the lanthanum (e.g., with $\mathrm{Ca}^{2+}$ ) and niobium (e.g., with $\mathrm{Sb}^{3+}$ ) sites can introduce oxygen vacancies according to the following equations and, respectively:

$$
\begin{aligned}
& 2 \mathrm{CaO}+\mathrm{Nb}_{2} \mathrm{O}_{5} \rightarrow 2 \mathrm{Ca}_{\mathrm{La}}^{\prime}+2 \mathrm{Nb}_{\mathrm{Nb}}^{\mathrm{x}}+V_{\mathrm{O}}^{*}+7 O_{\mathrm{O}}^{\mathrm{x}} \\
& \mathrm{Sb}_{2} \mathrm{O}_{3}+\mathrm{La}_{2} \mathrm{O}_{3} \rightarrow 2 \mathrm{Sb}_{\mathrm{Nb}}^{\prime \prime}+2 \mathrm{La}_{\mathrm{La}}^{\mathrm{x}}+2 V_{\mathrm{O}}^{*}+6 \mathrm{O}_{\mathrm{O}}^{\mathrm{x}}
\end{aligned}
$$

The increased number of oxygen vacancies present in the oxide can promote ion transport by increasing charge carriers. The increase in proton concentration is linked to the hydration process, that is, to the water uptake of the oxide in humid atmospheres.

In the last decade, the hydration energetics of proton conductors have received much attention; however, studies have mostly been limited to the barium and strontium zirconate systems [7-10]. For barium zirconate, a gradual rise of water uptake with decreasing temperature has been observed, showing enthalpy of hydration at levels of -22 to $-40 \mathrm{~kJ} \mathrm{~mol}^{-1}$ [7]. To the best of our knowledge, no directly measured data on water uptake are available for lanthanum orthoniobate and the only information on its hydration thermodynamics is based on transport measurements [3, 11, 12]. Haugsrud and Norby calculated enthalpy of hydration for $1 \% \mathrm{Ca}$-doped $\mathrm{LaNbO}_{4}$ to be $-115 \mathrm{~kJ} \mathrm{~mol}^{-1}$ [3], whereas Huse et al. reported even higher values based on modeling of titanium-doped material-approximately $-140 \mathrm{~kJ} \mathrm{~mol}^{-1}$ and $-170 \mathrm{~kJ} \mathrm{~mol}^{-1}$ in the case of nonassociated and associated defect models, respectively [11]. 
These numbers indicate that the difference in hydration energetics of barium zirconate and lanthanum orthoniobates is significant. The threefold difference between the hydration enthalpy values has to seriously affect the water uptake in these systems. In contrast, Ferrara et al. calculated the hydration enthalpy of lanthanum niobate from DFT studies for unstrained samples to be $-30 \mathrm{~kJ} \mathrm{~mol}^{-1}$ [13]. Such discrepancies in reported values reflect the complexity of the energetics of hydration of this system.

In this work, we report the thermogravimetric determination of water uptake of doped lanthanum orthoniobates for the first time.

\section{Experimental}

Following doped lanthanum orthoniobates were prepared and studied: $\mathrm{La}_{0.99} \mathrm{Ca}_{0.01} \mathrm{Nb}_{1} \mathrm{O}_{4-\delta}, \mathrm{La}_{0.98} \mathrm{Ca}_{0.02} \mathrm{Nb}_{1} \mathrm{O}_{4-\delta}$, $\mathrm{La}_{0.99} \mathrm{Ca}_{0.01} \mathrm{Nb}_{0.9} \mathrm{Sb}_{0.1} \mathrm{O}_{4-\delta}, \quad \mathrm{La}_{0.98} \mathrm{Ca}_{0.02} \mathrm{Nb}_{0.9} \mathrm{Sb}_{0.1} \mathrm{O}_{4-\delta}$, and $\mathrm{LaNb}_{0.9} \mathrm{Sb}_{0.1} \mathrm{O}_{4-\delta}$. The samples were synthesized using a two-step solid-state reaction described in detail elsewhere [5, 14]. Phase purity was determined by means of X-ray diffraction. The measurements were performed on a Phillips X'Pert Pro MPD diffractometer with $\mathrm{Cu} \mathrm{Ka}$ radiation in the $2 \theta$ range of $20^{\circ}-90^{\circ}$. The microstructure of the measured powders was characterized using a FEI Quanta FEG 250 scanning electron microscope operating in high vacuum mode. Thermogravimetric analysis was performed using a Netzsch Jupiter ${ }^{\circledR} 449 \mathrm{~F}$, following two experimental approaches. Firstly, the as-prepared powders were heated to $1273 \mathrm{~K}\left(1000{ }^{\circ} \mathrm{C}\right)$ and held at this temperature for $0.5 \mathrm{~h}$ under dry air to remove water and possible surface carbon dioxide. Lanthanum oxides are well known for their affinity to water; therefore, the drying step was required [15]. Our previous studies on lanthanum orthoniobate mass decay upon heating have shown that $1000{ }^{\circ} \mathrm{C}$ is sufficient to ensure complete desorption of adsorbed species (mainly water and carbon dioxide) [2]. The sample gas was then saturated with water $\left(\mathrm{P}_{\mathrm{H} 2 \mathrm{O}-}\right.$ $=0.023 \mathrm{~atm})$, and the mass change was recorded upon cooling. Data were collected every $100{ }^{\circ} \mathrm{C}$ in temperature range $1273-573 \mathrm{~K}\left(1000-300{ }^{\circ} \mathrm{C}\right)$, with a $2-4 \mathrm{~h}$ stabilization time at each temperature. Secondly, an isothermal approach was used, in which the samples were cooled to $573 \mathrm{~K}\left(300{ }^{\circ} \mathrm{C}\right)$ in dry gas after dehydration. After $2 \mathrm{~h}$ of stabilization, the dry gas was switched to humidified gas, and after an additional $2 \mathrm{~h}$, the wet gas was switched back to dry gas. Selected samples were also analyzed with the use of an isothermal approach where instead of $300{ }^{\circ} \mathrm{C}$ several temperatures in the range of $1073-473 \mathrm{~K}$ $\left(800-200^{\circ} \mathrm{C}\right)$ were used. Prior to each of the measurements, a blank run for baseline correction was carried out. To test the method used for measuring water uptake, a $\mathrm{BaZr}_{0.8} \mathrm{Y}_{0.2} \mathrm{O}_{3-\delta}(\mathrm{BZY})$ sample was analyzed, which was synthesized by a co-precipitation method as described elsewhere [16]. The obtained powder was preheated at $1473 \mathrm{~K}\left(1200{ }^{\circ} \mathrm{C}\right)$ to ensure uniformity of the grain size and to minimize the surface water adsorption. The mass change of $\mathrm{BaZr}_{0.8} \mathrm{Y}_{0.2} \mathrm{O}_{3-\delta}$ and temperature as a function of time under water partial pressure of $0.001 \mathrm{~atm}$. are presented in Fig. 1. It can be seen that the mass increase corresponding to water uptake proceeds in steps matching decreasing temperature periods. The water uptake begins at $1173\left(900{ }^{\circ} \mathrm{C}\right)$ and increases with temperature decrease. The total mass change between 1273 and $573 \mathrm{~K}$ is $0.5 \%$. This agrees well with the results observed by Yamazaki et al. [7] and therefore validates the system.

Room temperature water vapor sorption studies were undertaken on a Quantachrome iQ Autosorb apparatus in the relative pressure range $p / p_{0}$ from 0.05 to 0.9 . The surface of both powders and ceramics of antimony-doped lanthanum orthoniobate was characterized using X-ray photoelectron spectroscopy (XPS). The spectra were recorded on a Thermo Scientific K-Alpha + X-ray photoelectron spectrometer system operating at a base pressure of $2 \times 10^{-9}$ mbar. The system incorporates a monochromatic, microfocused $\mathrm{Al} \mathrm{K} \alpha \mathrm{X}$-ray source $(h v=1486.6 \mathrm{eV})$ and a $180^{\circ}$ double focusing hemispherical analyzer with a $2 \mathrm{D}$ detector. The X-ray source was operated at $6 \mathrm{~mA}$ emission current and $12 \mathrm{kV}$ anode bias, and an X-ray spot size of $400 \mu \mathrm{m}$ was used. Data were collected at $200 \mathrm{eV}$ pass energy for survey and $20 \mathrm{eV}$ pass energy for corelevel spectra, and a flood gun was used to minimize sample charging. Spectra were aligned assuming the $\mathrm{C} 1 s$ core line to be at the binding energy of $285.0 \mathrm{eV}$. All data were analyzed using the Avantage software package.

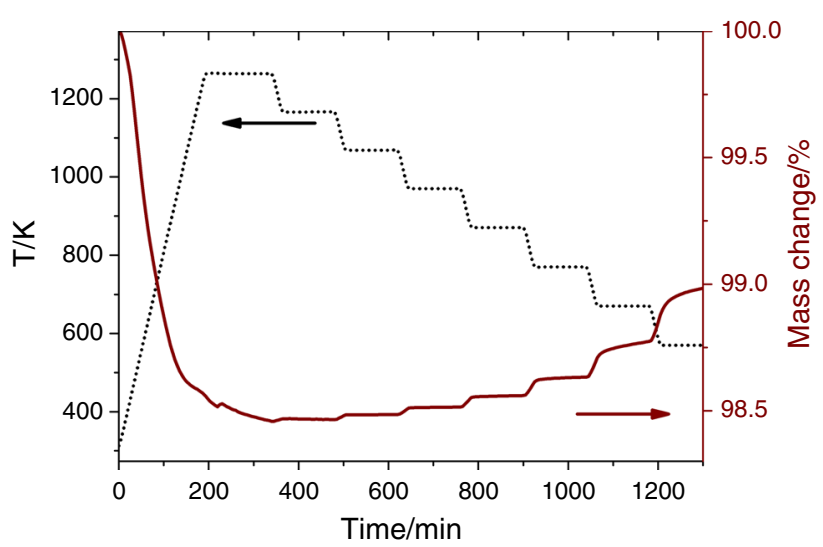

Fig. 1 Mass change of $\mathrm{BaZr}_{0.8} \mathrm{Y}_{0.2} \mathrm{O}_{3-\delta}$ sample and temperature as a function of time under water partial pressure of $0.001 \mathrm{~atm}$ 


\section{Results and discussion}

All reflections observed in the collected X-ray diffraction data for the different compositions could be indexed with a monoclinic fergusonite phase (I2/c). For samples co-doped with $2 \%$ antimony and calcium, additional small reflections of a secondary phase have been identified in the diffractogram. More information on the in-depth structural analysis of the investigated compounds can be found in previous works $[5,14,17]$.

Since the issue of surface adsorption in the case of powders has been previously reported [18-21], bulk powder samples were produced by solid-state synthesis method to ensure relatively small specific surface areas. Scanning electron microscopy analysis (see Fig. 2) shows that the resulting particle size is between 1 and $5 \mu \mathrm{m}$, confirming the synthesis of bulk powders, and it can be assumed that adsorption of water on the powder surface can be neglected even at low temperatures [22].

The lanthanum niobate samples studied in this work are acceptor-doped. Calcium $\mathrm{Ca}_{\mathrm{La}}^{\prime}$ always acts as an acceptortype defect in lanthanum niobate, whereas the role of antimony depends on its valence state. Figure 3 shows the $\mathrm{Sb} 3 d$ and $\mathrm{O} 1 s$ core-level spectra of $\mathrm{LaNb}_{0.9} \mathrm{Sb}_{0.1} \mathrm{O}_{4}$. (The
$\mathrm{La}$ and $\mathrm{Nb}$ core levels as well as the survey spectrum can be found in the Supplementary Information.) Two oxygen environments are observed with the dominant peak at $529.9 \mathrm{eV}\left(\mathrm{O}_{\mathrm{I}}\right)$ characteristic of the main oxide and the smaller peak at $531.5 \mathrm{eV}\left(\mathrm{O}_{\mathrm{II}}\right)$ stemming from, among other species, surface hydroxide. Two antimony environments are observed, with $\mathrm{Sb}^{3+}$ at binding energies of $529.6 \mathrm{eV}\left(3 d_{5 / 2}\right)$ and $538.9 \mathrm{eV}\left(3 d_{3 / 2}\right)$ and $\mathrm{Sb}^{5+}$ at binding energies of $530.3 \mathrm{eV}\left(3 d_{5 / 2}\right)$ and $539.7 \mathrm{eV}\left(3 d_{3 / 2}\right)$. Some weak satellites are also observed in the background around the $\mathrm{Sb} 3 d_{3 / 2}$ line. From a peak fit analysis of the $\mathrm{Sb}$ core level, which is complicated by the fact that the $\mathrm{Sb} 3 d_{5 / 2}$ core level sits under the $\mathrm{O} 1 s$ core level, the ratio between $\mathrm{Sb}^{3+} / \mathrm{Sb}^{5+}$ on the sample surface was determined to be 57:43. Therefore, it may be assumed that at the surface, approximately half of the antimony atoms substituting niobium plays the role of acceptor dopants $\left(\mathrm{Sb}_{\mathrm{Nb}}^{\prime \prime}\right)$, whereas the other half is isovalent with niobium $\left(\mathrm{Sb}_{\mathrm{Nb}}^{\mathrm{x}}\right)$. Within this assumption, the effective acceptor dopant content, denoted as [Acc], in the studied samples may be estimated as being between 0.01 and 0.12 , while the lowest and highest limits correspond to $\mathrm{La}_{0.99} \mathrm{Ca}_{0.01} \mathrm{Nb}_{1} \mathrm{O}_{4-\delta}$ and $\mathrm{La}_{0.98} \mathrm{Ca}_{0.02} \mathrm{Nb}_{0.9}$ $\mathrm{Sb}_{0.1} \mathrm{O}_{4-\delta}$, respectively. On the basis of these results and assuming neutrality conditions, the oxygen vacancy
Fig. 2 Scanning electron images of micropowders for a $\mathrm{La}_{0.99} \mathrm{Ca}_{0.01} \mathrm{NbO}_{4-\delta}$, b $\mathrm{La}_{0.98} \mathrm{Ca}_{0.02} \mathrm{NbO}_{4-\delta}$, c $\mathrm{La}_{0.99} \mathrm{Ca}_{0.01} \mathrm{Nb}_{0.9} \mathrm{Sb}_{0.1} \mathrm{O}_{4-\delta}$, d $\mathrm{La}_{0.98} \mathrm{Ca}_{0.02} \mathrm{Nb}_{0.9} \mathrm{Sb}_{0.1} \mathrm{O}_{4-\delta}$ specimens (a)

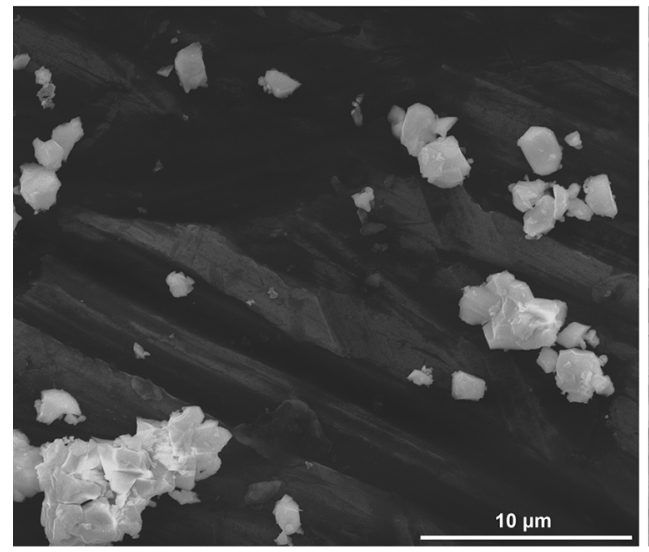

(c)

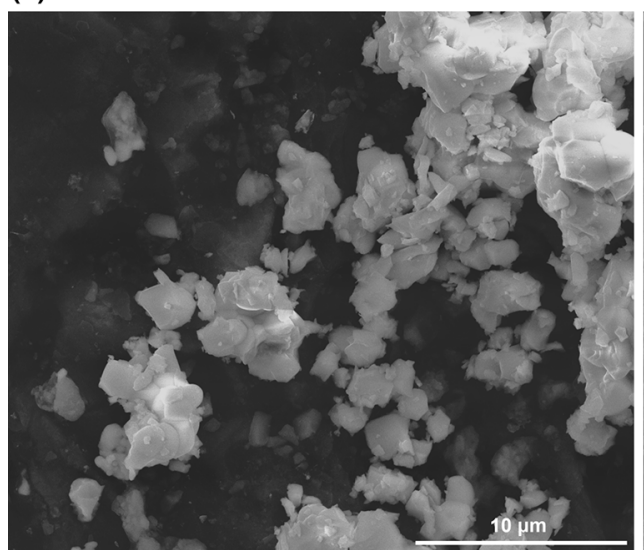

(b)

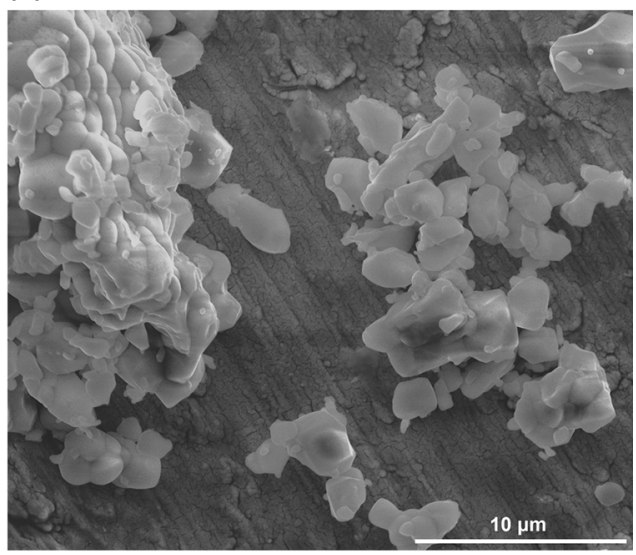

(d)

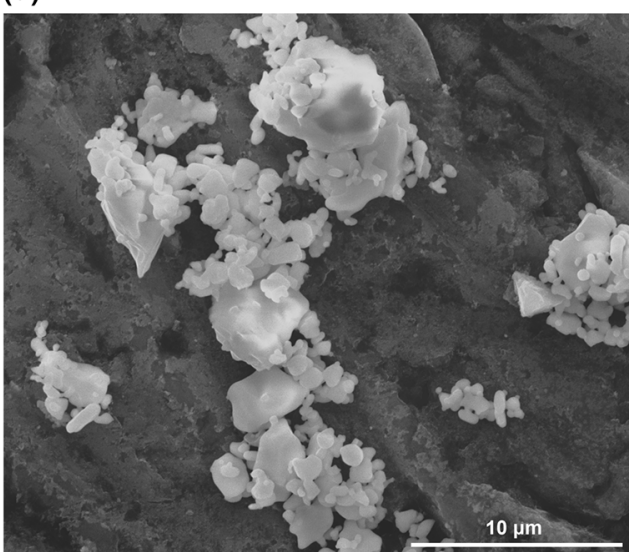




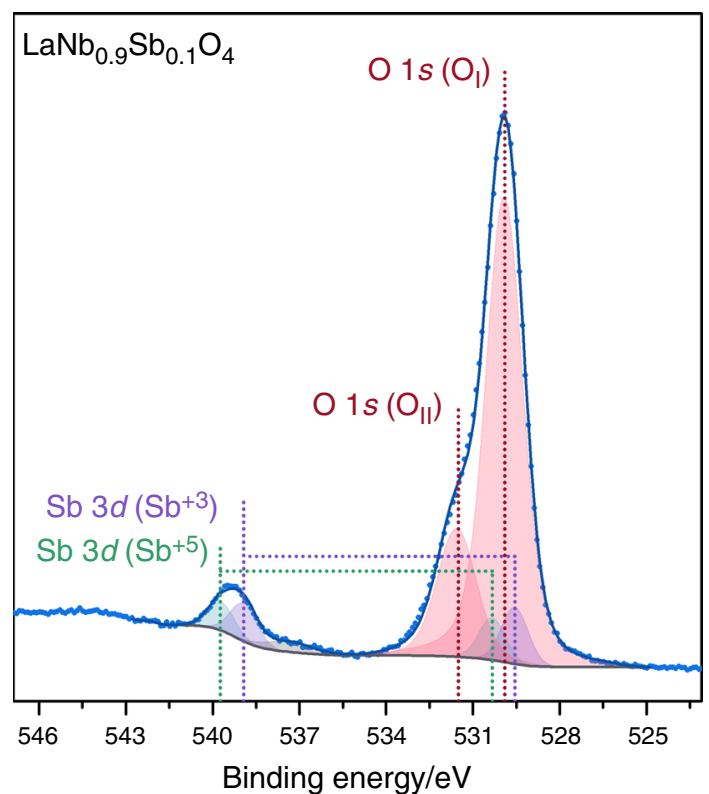

Fig. $3 \mathrm{Sb} 3 d$ and $\mathrm{O} 1 s$ XPS core-level spectra of $\mathrm{LaNb}_{0.9} \mathrm{Sb}_{0.1} \mathrm{O}_{4-\delta}$

fraction may be calculated. Values of estimated effective acceptor content, as well as other properties of all studied materials, are summarized in Table 1.

Figure 4 presents the mass changes of the $\mathrm{LaNb}_{0.9}$ $\mathrm{Sb}_{0.1} \mathrm{O}_{4-\delta}$ and $\mathrm{La}_{0.98} \mathrm{Ca}_{0.02} \mathrm{Nb}_{0.9} \mathrm{Sb}_{0.1} \mathrm{O}_{4-\delta}$ samples and temperature as a function of time under a water partial pressure of $0.023 \mathrm{~atm}$. For both samples, the mass change during the temperature decreases from 1273 to $573 \mathrm{~K}$ is $<0.1 \%$. However, the sample co-doped with calcium and antimony $\left(\mathrm{La}_{0.98} \mathrm{Ca}_{0.02} \mathrm{Nb}_{0.9} \mathrm{Sb}_{0.1} \mathrm{O}_{4}\right)$ shows a clear mass change resulting from hydration of the sample. The mass change of the sample doped solely with antimony $\left(\mathrm{LaNb}_{0.9} \mathrm{Sb}_{0.1} \mathrm{O}_{4}\right)$ is much smaller, and the mass of this sample even decreases below $773 \mathrm{~K}$. This means that the water uptake in lanthanum niobates is much lower than that in yttrium-doped barium zirconate observed both in this work (Fig. 1) and by Yamazaki et al. [7]. Therefore, to determine the water uptake for lanthanum niobate samples, we decided to perform the thermogravimetric analyses in isothermal conditions with the atmosphere switch from dry to wet air. The results for the isothermal switch at $573 \mathrm{~K}$ are presented in Fig. 5. Values of the water uptake and proton content versus effective acceptor concentration are shown in Fig. 6. The values for all investigated samples are relatively low. They are the lowest for the sample solely doped with $1-2 \%$ calcium, and they tend to increase with an increase in acceptor content. This indicates that, in accordance with reactions (1-3), the formation of oxygen vacancies due to doping influences hydration levels via the formation of proton defects within the structure.

One of the most interesting properties observed in Fig. 6 is the highest water uptake for the $\mathrm{La}_{0.98} \mathrm{Ca}_{0.02} \mathrm{Nb}_{0.9} \mathrm{Sb}_{0.1}$ $\mathrm{O}_{4-\delta}$ sample. The reason for such a large difference between the water uptake values of sole calcium- and calcium and antimony-substituted samples is the difference between the crystal structures of the materials. The data shown in Fig. 6 were obtained at a relatively low temperature of $300{ }^{\circ} \mathrm{C}$, which is below the structural phase transition for calcium-doped samples but above the one for antimony-doped ones. The transition between the hightemperature tetragonal scheelite to the monoclinic fergusonite structure occurs at approximately $773 \mathrm{~K}$ [23] and $473 \mathrm{~K}[14]$ in the samples doped only with calcium and the co-doped samples with $10 \mathrm{~mol} \%$ of antimony, respectively.

Electrical measurements of the compositions investigated here have shown tendencies which do not fit the hydration data in the past. The highest achieved conductivity values for doped lanthanum orthoniobates of $10^{-3} \mathrm{~S} \mathrm{~cm}^{-1}$ at $1223 \mathrm{~K}$ in atmospheres containing ca $2 \%$ $\mathrm{H}_{2} \mathrm{O}$ have been reached in 1 mol \% calcium doping in studies by Haugsrud and Norby [24]. In contract, the value at $1073 \mathrm{~K}$ for antimony-substituted samples was of the order of $10^{-4} \mathrm{~S} \mathrm{~cm}^{-1}$ [5]. In comparison, results for $\mathrm{BaZr}_{0.8} \mathrm{Y}_{0.2} \mathrm{O}_{3}$ investigated previously by the authors as well as Yamazaki et al. [7] show $5 \times 10^{-2}$ for $\mathrm{BaZr}_{0.8 \text { - }}$ $\mathrm{Y}_{0.2} \mathrm{O}_{3}$ versus maximum of $3 \times 10^{-3}$ for $\mathrm{La}_{0.98} \mathrm{Ca}_{0.02}$ $\mathrm{Nb}_{0.9} \mathrm{Sb}_{0.1} \mathrm{O}_{4-\delta}$ proton concentration at $300{ }^{\circ} \mathrm{C}$. One of the main differences between the two compounds is the nature of their charge transport. In the case of barium zirconate, proton conduction is accompanied by oxygen ion transfer, while lanthanum orthoniobate is a pure proton conductor [3].

To determine the temperature dependence of the water uptake of calcium-doped lanthanum orthoniobate, the isothermal switches between dry and wet atmosphere were
Table 1 Selected properties of studied materials

\begin{tabular}{llll}
\hline Material & [Acc] & \multicolumn{2}{l}{ Total conductivity at $1073 \mathrm{~K}, \mathrm{~S} / \mathrm{cm}$} \\
\cline { 3 - 4 } & & Wet air & Dry air \\
\hline $\mathrm{La}_{0.99} \mathrm{Ca}_{0.01} \mathrm{NbO}_{4-\delta}[3,24]$ & 0.01 & $1.0 \times 10^{-3}$ & $3.0 \times 10^{-4}$ \\
$\mathrm{La}_{0.98} \mathrm{Ca}_{0.02} \mathrm{NbO}_{4-\delta}[29]$ & 0.02 & $2.3 \times 10^{-4}$ & $\mathrm{n} / \mathrm{a}$ \\
$\mathrm{LaNb}_{0.9} \mathrm{Sb}_{0.1} \mathrm{O}_{4-\delta}[5]$ & 0.10 & $3.4 \times 10^{-5}$ & $1.7 \times 10^{-5}$ \\
$\mathrm{La}_{0.99} \mathrm{Ca}_{0.01} \mathrm{Nb}_{0.9} \mathrm{Sb}_{0.1} \mathrm{O}_{4-\delta}$ & 0.11 & $\mathrm{n} / \mathrm{a}$ & $\mathrm{n} / \mathrm{a}$ \\
$\mathrm{La}_{0.98} \mathrm{Ca}_{0.02} \mathrm{Nb}_{0.9} \mathrm{Sb}_{0.1} \mathrm{O}_{4-\delta}[5]$ & 0.12 & $3.1 \times 10^{-4}$ & $1.3 \times 10^{-4}$ \\
\hline
\end{tabular}



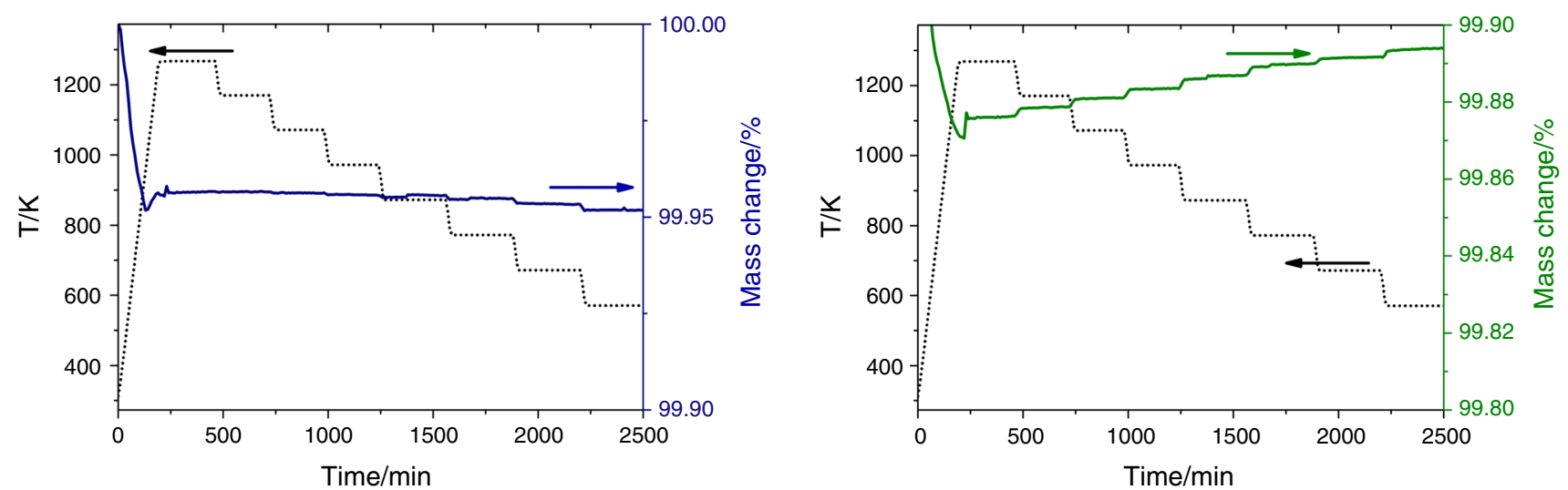

Fig. 4 Mass change of $\mathbf{a} \mathrm{LaNb}_{0.9} \mathrm{Sb}_{0.1} \mathrm{O}_{4-\delta}$ and $\mathbf{b} \mathrm{La}_{0.98} \mathrm{Ca}_{0.02} \mathrm{Nb}_{0.9} \mathrm{Sb}_{0.1} \mathrm{O}_{4-\delta}$ samples and temperature as a function of time under water partial pressure of $0.001 \mathrm{~atm}$

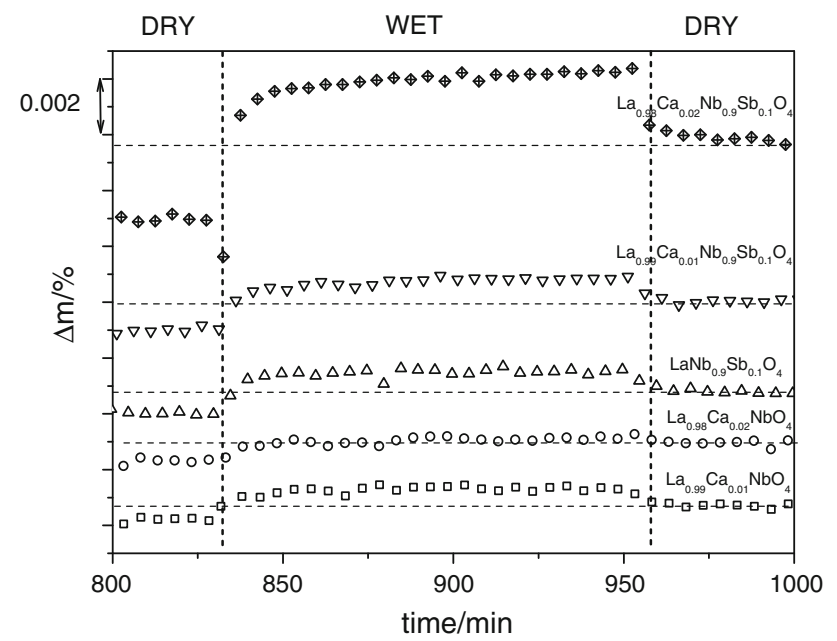

Fig. 5 Mass change of the investigated samples recorded at the isothermal switch at $300{ }^{\circ} \mathrm{C}$ between tank dry $\left(\mathrm{p}_{\mathrm{H} 2 \mathrm{O}}<0.0001 \mathrm{~atm}\right.$.) and humidified air $\left(\mathrm{p}_{\mathrm{H} 2 \mathrm{O}}=0.023 \mathrm{~atm}.\right)$

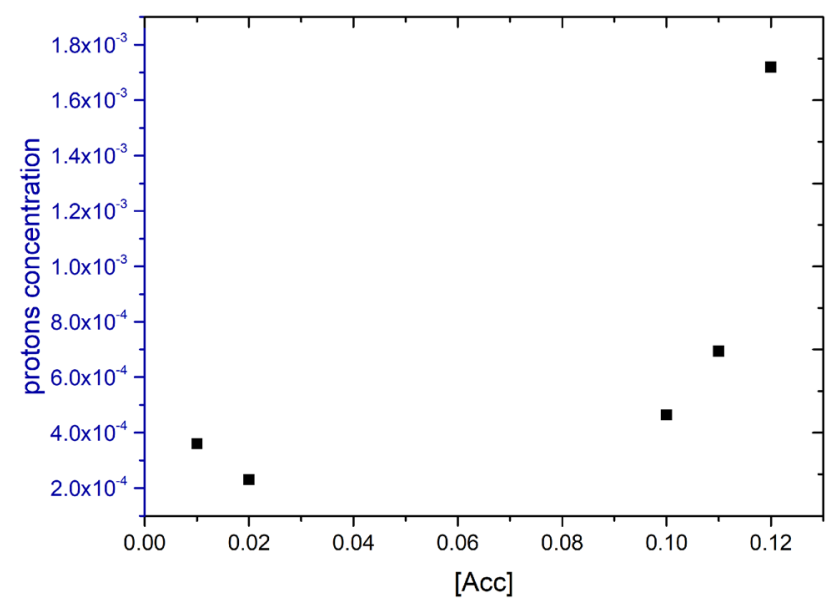

Fig. 6 Proton concentration at $300{ }^{\circ} \mathrm{C}(573 \mathrm{~K})$ versus estimated effective acceptor concentration

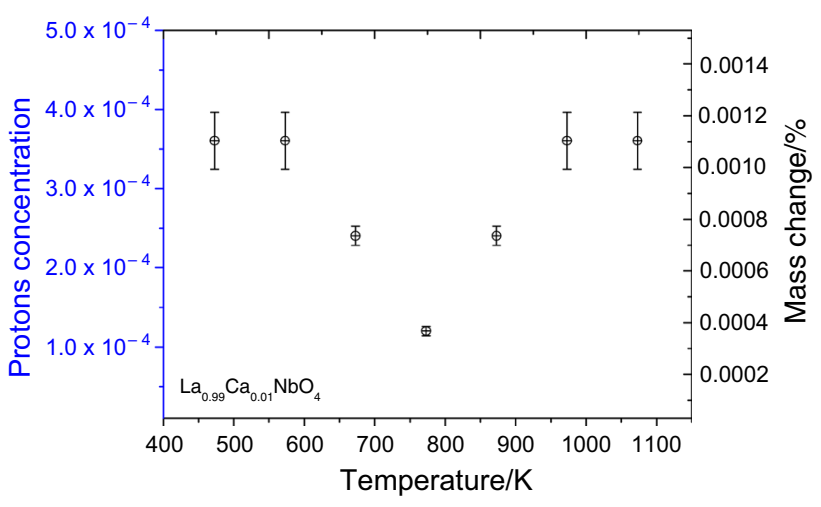

Fig. 7 Proton concentration as a function of temperature for $1 \mathrm{~mol} \%$ calcium-doped lanthanum orthoniobate

performed at various temperatures. The results for $\mathrm{La}_{0.99}$ $\mathrm{Ca}_{0.01} \mathrm{NbO}_{4}$ are shown in Fig. 7. The values of the water uptake varied from 0.01 to $0.03 \mathrm{mg}$, and apart from the temperatures close to the structural phase transition, the water uptake is temperature independent, yielding a total proton concentration per formula unit in the range of $10^{-4}$. This result shows that lanthanum orthoniobate allows water uptake across a wide range of temperatures. This is in contrast with other proton-conducting systems like barium zirconate-cerate, where hydration is strongly temperature dependent. Following the weak temperature dependence of the water uptake, a mean weak temperature dependency of the hydration reaction constant is expected following Eq. (1).

Given the set of defects described in Eqs. (1-3), the overall electroneutrality condition is given as:

$2\left[V_{\mathrm{O}}^{*}\right]+\left[\mathrm{OH}_{\mathrm{O}}\right]=[\mathrm{Acc}]$

Moreover, the number of oxygen sites per formula unit of lanthanum niobate is restricted to 4 , giving a site restriction relationship of: 
$\left[V_{\mathrm{O}}^{*}\right]+\left[\mathrm{O}_{\mathrm{O}}^{\mathrm{x}}\right]+\left[\mathrm{OH}_{\mathrm{O}}^{-}\right]=4$

In the analyzed case:

$[\mathrm{Acc}]=\left[\mathrm{Ca}_{\mathrm{La}}^{\prime}\right]$

With relationships (1-6), the equilibrium constant for the water incorporation reaction can be formulated as:

$$
\begin{aligned}
K_{\mathrm{w}} & =\exp \frac{\Delta S_{\text {hydr }}^{0}}{R} \exp \left(-\frac{\Delta H_{\text {hydr }}^{0}}{R T}\right)=\frac{\left[\mathrm{OH}_{\mathrm{O}}\right]^{2}}{p_{\mathrm{H}_{2} \mathrm{O}}\left[V_{\mathrm{O}}^{*}\right]\left[\mathrm{O}_{\mathrm{O}}^{x}\right]} \\
& =\frac{4\left[\mathrm{OH}_{\mathrm{O}}^{\cdot}\right]^{2}}{p_{\mathrm{H}_{2} \mathrm{O}}\left([\mathrm{Acc}]-\left[\mathrm{OH}_{\mathrm{O}}\right]\right)\left(8-[\mathrm{Acc}]-\left[\mathrm{OH}_{\mathrm{O}}\right]\right)}
\end{aligned}
$$

According to Eq. (6) in constant $p_{\mathrm{H}_{2} \mathrm{O}}$, the reaction constant depends only on $\left[\mathrm{OH}_{\mathrm{O}}\right]$ and $[\mathrm{Acc}]$. The TG data presented in Fig. 8 show weak temperature dependency, and from previous studies for calcium-doped lanthanum orthoniobate, there is no indication of any phase segregation with temperature $[23,25]$. As calcium has a stable $2+$ valence state, the acceptor concentration has to be constant with respect to temperature changes. The thermogravimetric data presented in Fig. 4 show a small temperature dependency of water uptake for investigated samples. Thus, one can estimate the hydration enthalpy to be low. This suggests that the reaction is favorable and therefore the limiting factor of proton incorporation is not the thermodynamics of hydration, but the diffusion of protonic defects in the crystal lattice.

The results illustrated in Fig. 7 show the minimum of the total water uptake at $773 \mathrm{~K}$. For lanthanum orthoniobate, this temperature is significant because of its structural phase transition [23], which changes the mobility of the charge carriers [26, 27]. It is possible that the coexistence of two separate orthoniobate phases, occurring during

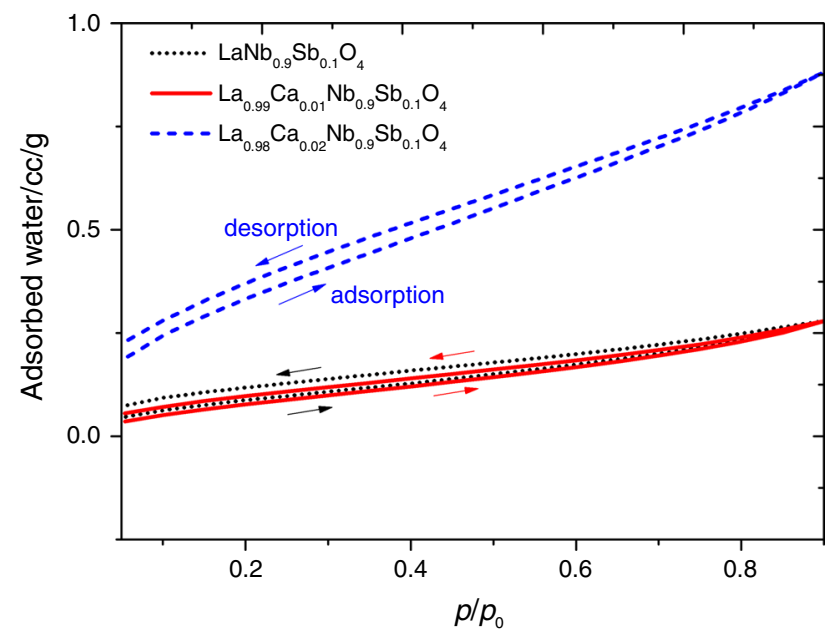

Fig. 8 Water vapor sorption isotherms at room temperature for samples with different dopant content phase transition [25], can influence the water uptake by changing proton defect pathways within the structure.

$\mathrm{Li}$ et al. studied strontium-substituted $\mathrm{LaNbO}_{4}$, which showed a low value of diffusion coefficient of protons in this structure [28]. The work suggests that the formation of stoichiometric impurities might have eliminated the surface oxygen vacancies, thus blocking water intake pathways between the gas phase and the oxide surface. A similar phenomenon may be present in our sample. This would help explain why even though the energetics of water uptake are thermodynamically favorable, the net water uptake is relatively small. The number of vacancies available for hydration is simply too small for the material to hydrate in an extensive way. This phenomenon can be either related to the segregation or the low surface diffusivity, which can be an intrinsic property of this system. This is in accordance with the results presented in Fig. 5 for different dopants and dopant concentrations and with the rise of the total water uptake with nominal acceptor content. Possible surface segregation can also be a reason for differences in room temperature water vapor sorption for materials with different dopant content (Fig. 8). For samples with higher acceptor dopant content, the surface is much more prone to adsorption. However, for all investigated samples, the total adsorbed water content is relatively low in comparison with other materials, especially nanocrystalline powders [19]. Therefore, at elevated temperatures, one can be sure that water uptake observed in lanthanum orthoniobates is due to bulk proton incorporation not surface phenomena. Presented results along with previous studies of electrical properties of doped lanthanum orthoniobates lead to the conclusion that introduction of antimony on the niobium site promotes water uptake in these compounds, since it enhances the proton conductivity in relation to the undoped material [5]. It is also possible that the proton defect mobility is different for a structure with antimony dopant. It is well known that antimony alters the structure and lowers the structural phase transition temperature, leading to changes in unit cell parameters. It was suggested that in antimony-doped lanthanum orthoniobate, the $(\mathrm{Nb}, \mathrm{Sb})-\mathrm{O}$ bond type is more covalent than that of $\mathrm{Nb}-\mathrm{O}$ [14], which can influence the proton diffusion pathways within the crystal lattice $[5,14]$. Slow diffusion can be a limiting factor for the hydration phenomena in this case. Since the lack of strong temperature dependence indicates a low hydration enthalpy, the low diffusivity can explain the slow hydration kinetics of the investigated system. 


\section{Conclusions}

The water uptake of antimony- and calcium-doped lanthanum orthoniobate has been analyzed by thermogravimetric studies. The relation between water uptake, material stoichiometry, and temperature has been studied. The weak temperature dependency of water uptake for all of the studied materials has been observed leading to the conclusion that the hydration reaction for lanthanum orthoniobate is favorable from the thermodynamic point of view. The low water uptake values have been assigned to possible low diffusivity of protonic defects in the structure. Further studies of the effect of surface segregation on the diffusion process are needed to fully understand the occurring phenomena.

Acknowledgements The research was financially supported by the Ministry of Science and Higher Education, Poland Grant No. IP2015 051374. The preparation of the samples for XPS examination has been supported by National Science Centre, Poland, by Grant No. 2015/17/N/ST5/02813. D.J.P. acknowledges support from the Royal Society (UF100105 and UF150693). D.J.P. and A.R. acknowledge support from the EPSRC (EP/M013839/1 and EP/M028291/1).

Open Access This article is distributed under the terms of the Creative Commons Attribution 4.0 International License (http://creative commons.org/licenses/by/4.0/), which permits unrestricted use, distribution, and reproduction in any medium, provided you give appropriate credit to the original author(s) and the source, provide a link to the Creative Commons license, and indicate if changes were made.

\section{References}

1. Norby T, Magrasó A. On the development of proton ceramic fuel cells based on Ca-doped $\mathrm{LaNbO}_{4}$ as electrolyte. J Power Sources. 2015;282:28-33.

2. Mielewczyk-Gryn A, Wachowski S, Zagórski K, Jasiński P, Gazda M. Characterization of magnesium doped lanthanum orthoniobate synthesized by molten salt route. Ceram Int. 2015;41(6):7847-52.

3. Haugsrud R, Norby T. Proton conduction in rare-earth orthoniobates and ortho-tantalates. Nat Mater. 2006;5:193-6. https:// doi.org/10.1038/nmat1591.

4. Syvertsen GE, Magrasó A, Haugsrud R, Einarsrud MA, Grande $\mathrm{T}$. The effect of cation non-stoichiometry in $\mathrm{LaNbO}_{4}$ materials. Int J Hydrogen Energy. 2012;37(9):8017-26.

5. Wachowski S, Mielewczyk-Gryń A, Zagórski K, Li C, Jasiński P, Skinner SJ, et al. Influence of Sb-substitution on ionic transport in lanthanum orthoniobates. J Mater Chem A. 2016;4:11696-707.

6. Vullum F, Nitsche F, Selbach SM, Grande T. Solid solubility and phase transitions in the system $\mathrm{LaNb}_{1-x} \mathrm{Ta}_{x} \mathrm{O}_{4}$. J Solid State Chem. 2008;181:2580-5.

7. Yamazaki Y, Babilo P, Haile SM. Defect chemistry of yttriumdoped barium zirconate: a thermodynamic analysis of water uptake. Chem Mater. 2008;20:6352-7. https://doi.org/10.1021/ cm800843s.

8. Yamazaki Y, Blanc F, Okuyama Y, Buannic L, Lucio-Vega JC, Grey $\mathrm{CP}$, et al. Proton trapping in yttrium-doped barium zirconate. Nat Mater. 2013;12:647-51. https://doi.org/10.1038/ nmat3638.

9. Yamazaki Y, Yang C-KK, Haile SM. Unraveling the defect chemistry and proton uptake of yttrium-doped barium zirconate. Scr Mater. 2011;65(2):102-7.

10. Ito T, Nagasaki T, Iwasaki K, Yoshino M, Matsui T. Water uptake and infrared absorption in $\mathrm{SrZr}_{0.95} \mathrm{M}_{0.05} \mathrm{O}_{3-\alpha}(\mathrm{M}=\mathrm{Ga}, \mathrm{Sc}$, y and Nd). J Therm Anal Calorim. 2005;81:545-8.

11. Huse M, Skilbred AWB, Karlsson M, Eriksson SG, Norby T, Haugsrud R, et al. Neutron diffraction study of the monoclinic to tetragonal structural transition in $\mathrm{LaNbO}_{4}$ and its relation to proton mobility. J Solid State Chem. 2012;187:27-34.

12. Fjeld H, Kepaptsoglou DM, Haugsrud R, Norby T. Charge carriers in grain boundaries of $0.5 \% \mathrm{Sr}$-doped $\mathrm{LaNbO}_{4}$. Solid State Ion. 2010;181:104-9.

13. Ferrara C, Eames C, Islam MS, Tealdi C. Lattice strain effects on doping, hydration and proton transport in scheelite-type electrolytes for solid oxide fuel cells. Phys Chem Chem Phys. 2016;18:29330-6.

14. Wachowski S, Mielewczyk-Gryn A, Gazda M. Effect of isovalent substitution on microstructure and phase transition of

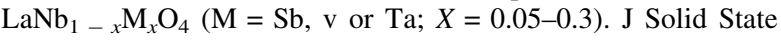
Chem. 2014;219:201-9.

15. Haibel E, Berendts S, Walter D. Thermogravimetric and X-ray diffraction investigation on carbonated lanthanum oxide and lanthanum hydroxide formed in humid $\mathrm{CO}_{2}$ atmosphere. $\mathrm{J}$ Therm Anal Calorim. 2018;134:261-7. https://doi.org/10.1007/s10973018-7256-1.

16. Zagórski K, Wachowski S, Szymczewska D, Mielewczyk-Gryń A, Jasiński P, Gazda M. Performance of a single layer fuel cell based on a mixed proton-electron conducting composite. J Power Sources. 2017;353:230-6.

17. Mielewczyk-Gryn A, Wachowski S, Lilova KII, Guo X, Gazda M, Navrotsky A. Influence of antimony substitution on spontaneous strain and thermodynamic stability of lanthanum orthoniobate. Ceram Int. 2015;41:2128-33.

18. Colomban P, Zaafrani O, Slodczyk A. Proton content and nature in perovskite ceramic membranes for medium temperature fuel cells and electrolysers. Membranes (Basel). 2012;2:493-509.

19. Dastan D. Effect of preparation methods on the properties of titania nanoparticles: solvothermal versus sol-gel. Appl Phys A. 2017;123:699. https://doi.org/10.1007/s00339-017-1309-3.

20. Dastan D, Chaure N, Kartha M. Surfactants assisted solvothermal derived titania nanoparticles: synthesis and simulation. J Mater Sci Mater Electron. 2017;28:7784-96. https://doi.org/10.1007/ s10854-017-6474-9.

21. Gruszkiewicz MS, Simonson JM, Burchell TD, Cole DR. Water adsorption and desorption on microporous solids at elevated temperature. J Therm Anal Calorim. 2005;81:609-15. https://doi. org/10.1007/s10973-005-0832-1.

22. Gonçalves MD, Maram PS, Muccillo R, Navrotsky A. Enthalpy of formation and thermodynamic insights into yttrium doped $\mathrm{BaZrO}_{3}$. J Mater Chem A. 2014;2:17840-7.

23. Mielewczyk-Gryn A, Gdula K, Lendze T, Kusz B, Gazda M. Nano- and microcrystals of doped niobates. Cryst Res Technol. 2010;45:1225-8. https://doi.org/10.1002/crat.201000378.

24. Haugsrud R, Norby T. High-temperature proton conductivity in acceptor-doped $\mathrm{LaNbO}_{4}$. Solid State Ion. 2006;177:1129-35.

25. Malavasi L, Ritter $\mathrm{C}$, Chiodelli G. Investigation of the high temperature structural behavior of $\mathrm{La}_{0.99} \mathrm{Ca}_{0.01} \mathrm{NbO}_{4}$ proton conducting material. J. Alloys Compd. 2009;475:L42-5.

26. Huse M, Norby T, Haugsrud R. Effects of A and B site acceptor doping on hydration and proton mobility of $\mathrm{LaNbO}_{4}$. Int $\mathrm{J}$ Hydrogen Energy. 2012;37:8004-16. 
27. Kreuer K. Aspects of the formation and mobility of protonic charge carriers and the stability of perovskite-type oxides. Solid State Ion. 1999;125:285-302.

28. Li C, Pramana SS, Ni N, Kilner J, Skinner SJ. Surface chemistry of $\mathrm{La}_{0.99} \mathrm{Sr}_{0.01} \mathrm{NbO}_{4-\mathrm{d}}$ and its implication for proton conduction. ACS Appl Mater. 2017;9:29633-42. https://doi.org/10.1021/ acsami.7b04856.
29. Bi Z, Peña-Martínez J, Kim J-H, Bridges CA, Huq A, Hodges JP, et al. Effect of $\mathrm{Ca}$ doping on the electrical conductivity of the high temperature proton conductor $\mathrm{LaNbO}_{4}$. Int $\mathrm{J}$ Hydrogen Energy. 2012;37:12751-9.

Publisher's Note Springer Nature remains neutral with regard to jurisdictional claims in published maps and institutional affiliations. 